\title{
Re-investigating the effect of individual determinant, external factor and firm characteristics on small firm performance during economic downturn
}

\author{
Esuh Ossai-Igwe Lucky* and Mohd Sobri Minai \\ College of Business, Universiti Utara Malaysia, Malaysia. \\ Accepted 2 August, 2011
}

\begin{abstract}
There have been inconsistencies with regard to the different entrepreneurial factors that influenced firm performance, particularly in normal time. However, during economic downturn or turbulence, it is believed and expected that the three major characters (entrepreneur, environment and firm) in the economy that are actively involved in entrepreneurial activities would be badly and negatively affected. Despite this, an empirical study substantiating these arguments seems to be lacking, particularly in the small business and entrepreneurship domain. This therefore suggests that some of the major influential factors of individual determinant, external factor and firm characteristics in entrepreneurial development and small businesses should be re-investigated in line with the current situation in order to see if they remain significant during economic downturn. Based on this, a cross-sectional study was conducted using a questionnaire survey research design, and data were generated from 182 entrepreneurs or owner-managers of small firms in both manufacturing and service industries. The questionnaires were distributed through drop-off and pick procedure of data collection. The findings indicated that the relationship between individual determinants, external factor and firm characteristics, and firm performance remain significant during economic turbulence.
\end{abstract}

Key words: Entrepreneurship determinants, entrepreneurship development, performance.

\section{INTRODUCTION}

There is no doubt that entrepreneurship development has been globally acknowledged as one of the instruments for achieving economic growth and development as well as employment creation (Rebecca and Benjamin, 2009). This is the more reason it has been given serious attention in many parts of the world as well as in the academic field. For instance, countries such as U.S.A, UK, Malaysia, Indian, China, Singapore, Thailand, Vietnam and a host of others have continued to emphasize on the important of entrepreneurship development. For example, Kuratko (2005) reported undoubtedly that the field of entrepreneurship development has saved "wealth" amounting to and has increased above $\$ 440$ million, with above $75 \%$ of those funds collected as of 1987 in U.S.A.

*Corresponding author. E-mail: igwedegreat@yahoo.com. Tel: +60104617732.
Similarly, studies have documented that SMEs account for about $88 \%$ of the small scale industries, while $12 \%$ is credited to the medium industries in Malaysia. In Singapore alone, SMEs absorbed half of the working population and consequently contributed about a third of the total value-added, forming $92 \%$ of the total number of industrial establishments which include manufacturing, commercial and service sectors (Chea, 2009). In Nigeria, the importance of entrepreneurship development cannot be overlooked. Its contributions are quite obvious. Rebecca and Benjamin (2009) reported that the small and medium scale firms have been increasing to the extent that they account for about $70 \%$ of the industrial employment, while the agricultural sector tends to absorb more than $60 \%$ of the country's workforce.

Furthermore, past studies on entrepreneurship development have asserted that factors such as individual determinant, external factor and firm characteristics significantly and positively affect firm performance (Blackman, 
2003; Colin et al., 2005; McClelland, 1961; Van de Ven, 1993; Kuratko and Hodgetts, 2004; Dean et al., 2000). Owning to this, one cannot doubt that past studies have really given attention to the impact of individual determinants, external factors and firm characteristics on firm performance (Rebecca and Benjamin, 2009; William, 2009; Yanfeng and Si, 2008; Okpara et al., 2007; Ogundele, 2007). However, despite the attention extended to these factors, Man et al. (2002) have argued that all these factors still deserve further attention, perhaps in a different environment in the study of entrepreneurship and small businesses. Accrodingly, although, these factors have been found to influence firm performance to different extents, the results are often inconsistent (Man et al., 2002; Yanfeng and Si, 2008; Kisfalvi, 2002; Dean et al., 2000; Pelham, 1999; Chandler and Hanks, 1994; Cooper, 1993). Therefore, the mix findings among authors suggest that further investigation on these factors should be conducted so as to ascertain their actual relationship with the small firm performance.

Previous studies have argued on the difference in environment and economic condition, as it could affect research findings to a greater extent (Okpara and Wynn, 2007; Sekaran et al., 2001). In Nigeria, a unique environment exists - an economic downturn or economic turbulence. For instance, Nwaobi (2009), Amuseghan and Tayo-Olajubutu (2009), Emma (2000), Ikeanyibe (2009), Ishola (2008) and Martins and Emmanuel (2009), have argued and thus maintained that Nigerian economy is in downturn. This therefore suggests that factors such as individual determinants, external factors and firm characteristics should be re-investigated in order to ascertain whether or not they remain valid in the new environment. During economic downturn or turbulence, it is believed and expected that the three major characters (entrepreneurs, environment and firm) in the economy that engage in entrepreneurial activities would be badly and negatively affected, thus making it difficult for these three major characters to significantly contribute to the overall performance of the firm as well as to the economy in general. For instance, in Nigeria in particular, it is reported that many firms have closed down operations and some have relocated to other neighboring countries, while the fate of the remaining ones are uncertain (MAN, 2009; Rebecca et al., 2009).

However, an empirical study substantiating these arguments seems to be lacking and therefore, may not exist particularly in the small business and entrepreneurship domain. This therefore suggests that the three major influential factors (Man et al., 2002) in entrepreneurial development and small businesses namely: individual characteristics, external factors and firm characteristics need to be re-investigated in line with the current situation as in the case of this research. Hence, this study tends to observe if the significant relationship between individual determinants, external factors and firm characteristics on the small firm performance remain valid and the same during the normal time or not. Thus, at the end of this study, it is expected that this would provide both theoretical and practical contributions in the field of entrepreneurship development.

\section{REVIEW OF RELATED LITERATURE AND HYPOTHESES DEVELOPMENT}

\section{Individual determinant}

The individual determinant is highly rooted in the psychology theory of entrepreneurship. Theorists of this concept have greatly stressed the need for entrepreneurs to possess certain entrepreneurial characteristics apart from those individual characteristics needed to develop entrepreneurship, and as such, it is imperative to examine the relationship between entrepreneurship development and individual characteristics. The individual characteristic could also be referred to as entrepreneurial characteristics or qualities. Within the context of this discussion, the individual determinant is being discussed under the perspective of individual characteristics. First, it is important to note that entrepreneurial firms are created by entrepreneurs who posses certain characteristics or personalities that enables them to manage the firm and achieve success. These characteristics are therefore needed for the development of entrepreneurship and thus form the vocal point of this discussion.

It is crystal clear that studies on entrepreneurs' characteristics are quite abundant, right from the time of the fore fathers of entrepreneurship development like Cantillon, Schumpeters, Say, McClelland and a host of others. For instance, Olanrewaju (2009) found that entrepreneurial characteristics strongly created an impact on entrepreneurial performance of small-scale business. William (2009) in assessing Zimbabwe's entrepreneurship noted that if all the requisite entrepreneurial and managerial skills which are the products of entrepreneurial characteristics are acquired either by the entrepreneurs themselves or by the management for SMEs, they could translate these skills into entrepreneurial performance. Therefore, there is positive relationship between entrepreneurial characteristics and entrepreneurial development. In line with this, Mohd (2005) noted that entrepreneurial characteristics can influence the type of firm that will be created as well as how it will be managed. Thus, it is important to understand the entrepreneurial characteristics of the entrepreneurs.

Several studies have listed the personality characteristics needed to develop entrepreneurship as to include among others: the need for achievement and motivation, knowledge, skills, locus of control, etc. Blackman (2003) asserted that an individual's characteristics are both attributed to his achievement which also has direct effect to the entrepreneurial firm performance. Colin et al. (2005) argued that there is a little point in trying to match 
yourself up to this or that personality type. However, there are some fairly broad characteristics that are generally accepted as being essential if one is going to make a success of the entrepreneurial firm in terms of its performance. Supporting these aforementioned arguments, Lawal (2005) and Ogundele (2007) in their studies of indigenous entrepreneurial development found that entrepreneurial characteristics, which they called personal and psychological factors, affected entrepreneurial performance.

Furthermore, being fully aware of the complex nature of the individual determinants' variable in the academic field of entrepreneurship development in which no single study can cover at a glance, concentrating on a few variables of individual determinants most especially at the individual level would be better and fruitful instead of lumping everything into one single factor. In this case, bearing in mind their crucial importance and the unique nature upon which the research is being conducted, therefore, this study considered and focused on five crucial variables of individual determinants: mental capacity, motivation and needs, gender, biological make up and attitude, which are in this study called individual determinants.

\section{External determinant}

External determinant has been described in various ways. For instance, it has been seen to mean situations in the environment, while other studies viewed it as conditions found in the entrepreneurial environment. Mohd (2005) has also described it as some factors that are capable of dictating the failure and success of the entrepreneurial firms or entrepreneurs themselves. The role of external environment has been widely recognized in determining and dictating the performance and the continued existence of the entrepreneurial firms, most especially in this critical time. Therefore, there is need to examine the entrepreneurship development with respect to the external environment. Several studies have really examined the impact of external environment on entrepreneurial performance. Hence, some body of knowledge exists in this regard. For instance, Mohd (2005) has shown that external factors have a very vital role to play in the determination of the failure or success of the entrepreneurial firms. Another study has asserted that external factors can assign boundaries to entrepreneurial firms and entrepreneurs' decisions, and on the other hand provide opportunities from the environment. Similarly, Van de Ven (1993) has argued in his work that any study in the field of entrepreneurship which does not regard other variables such as the environment should be regarded as insufficient and incomplete. He asserted that research in entrepreneurship should try to look at or view entrepreneurship in a social system perspective, which on the other hand gives attention to external environmental conditions and thus should be considered more appropriate in the explanation of the entrepreneurial process.

Supporting this, Arowomole (2000) noted that the various factors, forces and actors that make up the external determinant could be problems or opportunities to the entrepreneurs and therefore can effectively determine or influence the entrepreneurial competence and performance of the entrepreneurs. Kuratko and Hodgetts (2004) also showed that external factors could directly or indirectly affect or influence entrepreneurial decisions, thereby also affecting the performance.

However, the external factor in this study only reflects the economic and environmental factors which form part of the dimensionality of the external factor. This is in line with Kader et al. (2009) who regarded external factor in this perspective. Besides, being fully aware of the diverse and dimensionality nature of external factor like that of individual determinants variable in the academic field of entrepreneurship development in which no single study can fully cover, dwelling on a few dimensions like economic and environmental elements becomes more imperative in order to achieve a better and fruitful result instead of lumping everything into one single factor. Therefore, this study considered and focused on the economic and environmental dimension of the external factor.

\section{Firm characteristics}

Entrepreneurial firms are being managed by the entrepreneurs. Some of these firms are micro, while others are small in size. Again, these firms could also be old or new, with various management styles. The nature of the firm, size of the firm and entrepreneurs' firm knowledge are very crucial. All these form the firm's characteristics and could greatly affect entrepreneurial development. Therefore, it is essential to examine the significant relationship between entrepreneurship development and the entrepreneurial firm's characteristics. Previous studies have documented the relationship between firm characteristic and entrepreneurship. For instance, Mohd (2005) asserted that firm characteristics seem to play a vital role in determining the performance of the firm and can further determine how well entrepreneurship have been developed in the country. Wiklunda and Shepherd (2005), using the logic of the configuration approach, arrived at the premise that firms which are able to align certain firm attributes with the characteristics of the environment outperform others. Hence, those firms that failed to achieve such alignment will eventually be competed out. They further argued that a limited number of configurations of firm and environmental attributes can be used to describe large proportion of high-performing firms. They however, summarized the characteristics of an entrepreneurial firm as "the one that engage in product market, innovation, undertakes somewhat risky ventures, and is first to come up proactively". Dean et al. (2000) also reported that size affects a firm's marketing capabilities, attitudes, needs, practices, etc., which are 
important determinants of firms' performance and success.

In line with the aforementioned, some studies have examined the relationship between firm size and export performance which they measured by annual sales. The result was found to be fairly straightforward in terms of the effect of the size which was measured by annual sales. Also, Wagner in his study found that firm size measured by annual sales had a positive impact on export sales of the entrepreneurial firm. However, Dean et al. (2000) reported that the connection between firm size, which is contained in the firm's characteristics and entrepreneurial performance, is a controversial issue in the field of research. They argued that there is a little in common with the measurement of size, whereas the traditional concept is usually indicated by assets, employees and sales. In support of this argument, Dean et al. (2000) asserted that other studies which have investigated the use of size to identify gap between group differences produced mixed results. Another study also gave a similar report on summarizing the major findings of five studies based on an extensive review of existing literatures with all the authors, and concluded that the empirical findings on the relationship between firm size and export intensity (entrepreneurial performance) are all mixed findings.

\section{Economic downturn vs. individual determinant, external factor, firm characteristics and firm performance}

Economic downturn has been connoted with many names such as economic meltdown, economic recession or crisis (Fabunmi and Isah, 2009; Emma, 2000). However, there is no commonly accepted definition of economic downturn. IMF regards periods when global growth is less than $3 \%$ to be economic downturn. In economics, an economic downturn is a general slowdown in economic activity over a long period of time, or a business cycle contraction. Emma (2000) argued that economic downturn is so drastic that the business and trade activities slowed down, thus affecting the entrepreneurs and the environment, including the firm. Accordingly, Iwere (2010) noted that economic condition has a lot of influences on the entrepreneurial development of any country. In relation to these, Brunello (2009) argued that during economic downturn, human capital, which includes entrepreneurs and other factors, may suffer. Therefore, during such periods, entrepreneurs' determinants such as attitude, motivations, mental capacity, etc. may depreciate; thus, the business environment (which includes all external factors) may also become unconducive and unfavorable for entrepreneurs to invest and conduct their business activities, while the firms may be closed down by the entrepreneurs. For instance, MAN (2009) noted that during economic downturn, many firms and businesses closed down, seize operation or seize to exist. Thus, at the end, the overall performance of the entrepreneurs, environment and the firm itself was affected.

Based on these discussions and coupled with the proposed research framework of this study, the following hypotheses were hereby formulated:

$\mathrm{H}_{1}$ : The relationship between individual determinant (attitude, motivation and needs, mental capacity, biological make up and gender) and firm performance will remain valid and significant during economic downturn.

$\mathrm{H}_{2}$ : The relationship between external factor and firm performance will remain valid and significant during economic downturn.

$\mathrm{H}_{3}$ : The relationship between firm characteristics (firm size, nature of firm and firm knowledge) and firm performance will remain valid and significant during economic downturn.

Figure 1 shows the research model for the aforementioned hypotheses.

\section{METHODOLOGY}

\section{Sampling procedure}

First, a pilot study was initially conducted on thirty (30) ownermanagers within the locality in order to preliminarily assess the existing scale and modify it to suit the context of this present study. A simple random sampling was applied to select 300 small businesses and firms from the population of the study. The population of the study comprised a total number of 4425 small firms which were identified and sorted out through the local Lagos business directory. The choice of Lagos state was as a result of its business and as the industrial hub of the nation. According to the Lagos state government, 60 to $70 \%$ of business and industrial transactions in Nigeria is being concluded and finalized in Lagos. The state alone accounts for over $60 \%$ of the industrial value investment among other six main industrial zones or centers in the country (Akande et al., 2008; Adelakun, 2010). Each respondent was given equal chance of being chosen.

The following criteria were also applied to select the participants of the study:

(1) Businesses that have over three years of existence.

(2) Relatively standard and permanent business location.

(3) Availability of records of operation.

(4) A relatively organized setting.

Data for this study were obtained via a questionnaire survey after the respondents were first contacted via E-mail and phone to inform them about the survey. Then the questionnaires were distributed through drop-off and pick procedure of data collection to both the owner-managers and entrepreneurs of small firms in three major areas as categorized by the Lagos state government in Lagos State. A total of 230 completed questionnaires were returned filled, thus, giving $77 \%$ response rate of the total sample. However, the returned completed questionnaires were further reduced to a total sample of $201(67 \%)$ for the fact that some of the returned questionnaires were not properly filled and as such were not used for this study. Again, the sample was further reduced to 182 in the course of outliers and normality treatment. Therefore, the actual sample used in this study for the analysis was 182, giving a 


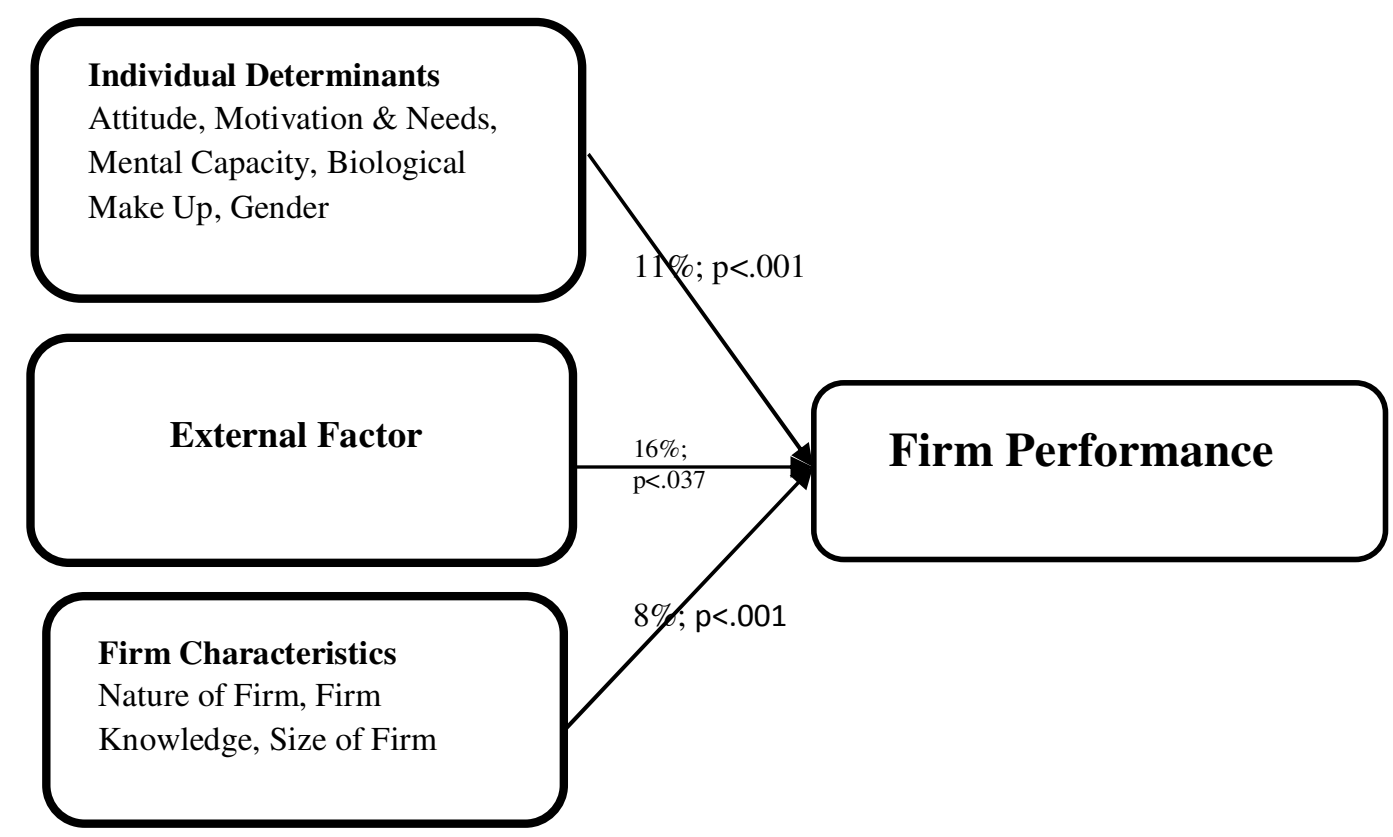

Figure 1. Research model.

response rate of $61 \%$.

\section{Measures}

First, all items in this study were measured using 5-point Likert scale ranging from 1 (strongly disagree) to 5 (strongly agree) to measure the extent to which respondents agree or disagree to each of the statement or questionnaire.

\section{Individual determinants}

The individual determinants were conceptualized as entrepreneurial characteristics and it was measured based on 5-point Likert scale which was adapted from the work of Francisco and Yi-Wen (2006) and Ogundele (2000). A total of thirty-seven questionnaire items comprising nine items for mental capacity, ten items for motivation and needs, eight items for attitude, five items for gender and five items for biological make up, adopted from Francisco et al. (2006) and Ogundele (2000), were utilized to measure the variable.

\section{External factor}

External factor which was also conceptualized as the economic and environmental factors were measured on a 5-point Likert scale adopted from Radiah et al. (2009). Eight questionnaire items adopted from the work of Radiah et al. (2009) were used to measure the variable.

\section{Firm characteristics}

This instrument was conceptualized as firm size, nature of firm and knowledge of the firm, and measured on the 5-point Likert scale with items adapted from the work of Ensley and Amason (2000). Fifteen questionnaire items comprising three items for firm nature, five items for firm size and seven items for firm knowledge adapted from the work of Ensley et al. (2000) were utilized to measure the variable.

\section{Firm performance}

This study utilizes the profitability and growth objective measure of financial and non-financial to measure firm performance. Both Murphy et al. (1996) and Ensley et al. (2000) have asserted that profitability and growth objective measure of measuring firm performance is appropriate, since it is always in line with the company's objective. Ten items with two dimensions of profitability and growth adapted from the work of Francisco et al. (2006), Ensley et al. (2000), Shradha et al. (2005) and Murphy et al. (1996) were utilized to measure the variable.

\section{DATA ANALYSES TECHNIQUES AND RESULTS}

The data collected from the main survey were subjected to data cleansing and cleaning in order to identify the missing value and sample characteristics, and meet the assumptions of normality. A factor analysis was conducted on all the variables in this study. Within the individual determinants variable, the variable yielded a five-factor model based on the underlying variable structure of dimensions of the theoretical framework of this study via a principle component factor analysis with varimax rotation. However, out of the thirty seven items used to measure this variable, seven items were dropped for the reason of not meeting the acceptable limit level of above 0.5 as suggested by Michael et al. (2000). Similarly, the external factor yielded a one-factor model as hypothesized via a principle component factor analysis with varimax rotation. All the eight items were loaded above the acceptable limit of above 0.5 (Michael et al., 2000). 
Table 1. Reliability and validity scores by the construct used in this study ( $N=182)$.

\begin{tabular}{lccc}
\hline Variable & Item no. & Cronbach's alpha scores & KMO \\
\hline Individual determinant & 27 & 0.840 & 0.721 \\
External factor & 8 & $\mathbf{0 . 8 5 3}$ & 0.834 \\
Firm characteristics & 13 & 0.857 & 0.829 \\
Firm performance & 10 & 0.820 & 0.837 \\
\hline
\end{tabular}

Accordingly, the firm characteristics variable yielded a three-factor model based on the underlying variable structure of dimensions of the theoretical framework of this study via a principle component factor analysis with varimax rotation. Two items from nature of firm were dropped for not meeting the acceptable loading limit. However, the rest items loaded above the acceptable limit and were retained. After this, the reliability and validity tests were also conducted.

In the reliability test, the variable with less than Cronbach' alpha coefficient of 0.50 was not included in the analysis. All variables indicated a factor loading level above the accepted limit of Cronbach's alpha coefficient of 0.50 as reported by Michael et al. (2000). Equally, the variables were subjected to validity test using Bartlett's test of sphericity (Muhammad, 2009). Within this study, the $\mathrm{KMO}$ for the construct were all above 0.6 as recommended by Chakraborty (2010), Trent et al. (2009), Nuradli et al. (2008) and Dahal (2004). Table 1 shows both the results of the Cronbach alpha and KMO of this study.

\section{Statistical analysis}

All variables used in this study are individual-level analysis, meaning that the unit of analysis is on individual level, comprising entrepreneurs and owner-managers in the selected firms. Two major data analyses' techniques were applied in this study. First, the study used the correlation analysis to confirm the data as well as the hypotheses in order to establish the strength of the relationship between the independent and dependent variables. Accordingly, the multiple regression analysis was equally applied to test the hypotheses in order to establish the nature of the relationship between the predictor and outcome variables. Hence, the multiple regression analysis was used to test the direct relationship hypothesized in this study as mentioned previously. The findings of the first three hypotheses based on correlation analysis are presented in Table 2 . The results indicate that:

1) There is a significant relationship between individual determinant and firm performance during economic downturn $(r=399, p<0.01)$.

2) There is a significant relationship between external factor and firm performance during economic downturn ( $r$ $=155, \mathrm{p}<0.05$ ).

3) There is a significant relationship between firm characteristics and firm performance during economic downturn $(r=472, p<0.01)$.

\section{Multiple regression analysis result}

To further test for the relationship indicated in the hypotheses, as well as in the research framework, a multiple regression analysis was conducted which was based on the higher level order. Thus, all variables were based on the mean centre (Lahiri and Kedia, 2009). Therefore, the individual determinant, external factor and firm characteristics represented by the calculated mean were entered into the regression model in order to ascertain their effect or impact on the dependent variable. The overall result of the significant values of each analysis conducted indicates that the hypotheses are significant.

From the first hypothesis $\left(\mathrm{H}_{1}\right)$, the result indicated that individual determinants which comprised attitude, motivation and needs, mental capacity, biological make up and gender was statistically significant at 0.000 $(p<0.001)$ with $R^{2}=0.159$ and at standard beta of 0.106 $(11 \%)$, thus suggesting that the elements of individual determinants significantly affected firm performance. Similarly, the result of the second hypothesis $\left(\mathrm{H}_{2}\right)$ indicated statistical significance in the external factor of $0.037(p<0.05)$ with $R^{2}=0.024$ and a standard beta of $0.155(16 \%)$. This result further suggested that external factor significantly affected firm performance. Finally, the third hypothesis $\left(\mathrm{H}_{3}\right)$ was equally tested using the standard multiple regression and the result indicated a statistical significance. This indicates that firm characteristics which comprise nature of firm, firm knowledge and size is statistically significant at $p<0.000(p<0.001)$ with $R^{2}=0.222$ and standard beta of $0.219(22 \%)$. Details of the regression analyses result are provided in Table 3.

\section{FINDINGS AND DISCUSSION}

This present study proposes that the relationship between individual determinant, external factor and firm characteristics, on firm performance remain valid and significant during economic downturn. 
Table 2. Correlation analysis among variables.

\begin{tabular}{lcccc}
\hline Variable & Individual determinant & External factor & Firm characteristics & Performance \\
\hline Individual determinant & 1 & & & \\
External factor & $0.229^{\star *}$ & 1 & & \\
Firm characteristics & $0.621^{* *}$ & $0.311^{* *}$ & 1 & 1 \\
Performance & $0.399^{\star *}$ & $0.155^{*}$ & $0.472^{\star *}$ & 1 \\
\hline
\end{tabular}

${ }^{*} \mathrm{P}<0.05 ;{ }^{*} \mathrm{P}<0.01, \mathrm{n}=182$.

Table 3. Multiple regression analysis summary for the predictor variables.

\begin{tabular}{lcccccccc}
\hline Variable & $\mathbf{R}$ & $\mathbf{R}^{2}$ & Adjusted $\mathbf{R}^{2}$ & Std. error of the estimate & $\mathbf{F}$ & Std. Beta & $\mathbf{t}$ & Sig. \\
\hline Individual determinants & 0.399 & 0.159 & 0.154 & 0.16448 & 34.049 & 0.106 & 5.835 & $0.000^{* * *}$ \\
External factor & 0.155 & 0.024 & 0.019 & 0.17720 & 4.417 & 0.155 & 2.102 & $0.037^{*}$ \\
Firm Characteristics & 0.472 & 0.222 & 0.219 & 0.15816 & 51.476 & 0.078 & 7.175 & $0.000^{* * *}$ \\
\hline
\end{tabular}

$\mathrm{P}<.01^{*}, \mathrm{p}<.05^{* *}, \mathrm{p}<.001^{* * *}$

Therefore, a cross-sectional study was conducted using a questionnaire survey research design, and the data were generated from 182 entrepreneurs or ownermanagers of small firms in both manufacturing and service industries, after which the hypotheses were tested using a multiple regression analysis.

The empirical findings presented in this study provided significant insights concerning the effect of individual determinant, external factor and firm characteristics on firm performance during economic downturn.

First, the individual determinant, which comprises gender, metal capacity, motivation and needs, attitude and biological make up, indicates a significant relationship with firm performance, thus suggesting that entrepreneurial determinants are crucial factors in the development of entrepreneurship and small business both in normal time and during a turbulent period. This result is consistent with the findings of Blackman (2003), Colin et al. (2005) and McClelland (1961) who asserted that there is a significant relationship between individual determinants and firm performance. Therefore, in summary, individual determinants of entrepreneur which comprise metal capacity, motivation and needs, attitude and biological make up should be given a serious consideration in an attempt to develop entrepreneurship and small business during normal time as well as in economic turbulent periods.

Secondly, the result of $\mathrm{H}_{2}$ indicates that external factor remains significant during economic downturn in predicting firm performance. This is consistent with the findings of Van de (1993), Yanfeng et al. (2008) and Kader et al. (2009) on the significant of external factor in the development of entrepreneurship. This result suggests that external factor is a vital component of entrepreneurship development and hence is very crucial in the development of entrepreneurship and small businesses during normal and economic downturn periods. This supports the findings of Van de (1993) who asserted that entrepreneurship development without external factor is incomplete. The result perhaps indicates that only entrepreneurial polices are being affected during economic downturn and not the external factors thought of by some people. In summary, the results suggest that entrepre-neurs / business owners and policy makers should always give a serious consideration to external factor in developing the nations' entrepreneurship and small business. This would bring about a positive result and change in the nations' entrepreneurship and small business.

Finally, the finding from the third hypothesis testing indicates that firm characteristics are still relevant and valid in developing small business and entrepreneurship during economic downturn. The firm characteristics which include, firm size, firm knowledge and nature of the firm is found to be significant in the analysis. The result indicates that firm characteristics are good predictors of small firm performance during economic turbulence. The result is consistent with past studies (Dean et al., 2000) which indicate a significant relationship between firm characteristics and firm performance particularly during economic downturn upon which the present study is being conducted. The results suggest that firm size, firm knowledge and nature of firm are important elements in achieving firm performance. The entrepreneurs/business owners should therefore always give considerations to elements such as firm size, firm knowledge and nature of firm in the course of small business and entrepreneurship development, as doing this would help them to achieve a positive result during normal and turbulent periods, and this in turn would bring about a positive firm performance.

The study offers two major contributions both in theoretical and practical perspectives. First, with respect to the theoretical contribution, testing these variables on a unique environment, such economic downturn is a big 
contribution to the body of literature in the academic field of entrepreneurship as the first to undertake a study of this nature. Secondly, the study would be useful to the practitioners, that is, both the entrepreneurs / ownermanagers and the policy makers, as the study offered them useful information on how to utilize these factors during economic downturn.

\section{Conclusion}

Within the context of the hypotheses tested in this study and the findings obtained, the following conclusions are therefore made:

1) The results confirmed that the significant relationship between individual determinant, external factor and firm characteristics, and firm performance remain valid and the same during economic downturn.

2) However, in overall, individual determinant, external factor and firm characteristics are very significant in determining small firm performance as well as in the development of entrepreneurship, most especially in Nigeria, during economic downturn.

\section{LIMITATION AND SUGGESTION FOR FUTURE STUDY}

Obviously, there is no research without limitations. Therefore, the findings of this study should be interpreted in the light of the following limitations. First, although, this study has reported significant findings, the generalization of this finding could be limited to both manufacturing and service sectors as covered by this study. Consequently, future studies in this field should endeavor to include other sectors like distribution and marketing firms which host many entrepreneurial and small firms. This is because the more a research findings is generalizable, the greater the usefulness as well as its value, as argued by Sekaran et al. (2000). Based on the environment upon which this study is conducted, we therefore recommend first that this study should also be replicated in a similar environment in order to validate the findings. Secondly, this study specifically investigated the effect of individual determinants, external factor and firm characteristics on firm performance in a unique environment using a crosssectional quantitative method, and thus, was limited to a questionnaire survey data collection. Several arguments exist on the most effective research method by researchers. Therefore, other research methods such as longitudinal study with qualitative data should be applied in order to see if the same result could be obtained, thus meriting further investigation.

\section{REFERENCES}

Akande OO, Ojukuku RM. (2008). The impact of entrepreneurial skills on small business performance in Lagos - South-Western Nigeria. World Conference. Halifax, Nova Scotia: International Council for Small Business.
Amuseghan SA, Tayo-Olajubutu A (2009). Spinning off an entrepreneurship culture among nigerian university students: prospects and challenges. Afr. J. Bus. Manage., 3(3): 080-088.

Arowomole KA (2000). Modern business management (Theory and Practice). 1st Edition. Sango-Ota, Ogun State: Ade-Oluyinka Commercial Press

Blackman AJ (2004). Entrepreneurs: interralationship between their characteristics, nalues, expectations management practices and SME performance.

Brunello G (2009). The effect of economic downturns on apprenticeships and initial workplace training: A Review of the Evidence. University of Padova, CESifo and IZA

Chakraborty S (2010). A study of select discount store retail in hyderabad for the purpose of identifying factors in regards to shopping motives, store attributes, shopping outcomes and perceived shopping cost. Int. J. Glob. Bus., 3(1): 1-19.

Chandler G, Hanks S (1994). Founder competence, the environment, and venture performance. Entrep. Theor. Pract., 18(3): 77-89.

Chea P (2009). Relationship between entrepreneurs' value, firm financing, market practices and growth performance of small-medium enterprises in cambodia. Sintok, Kedah, Malaysia: PhD Thesis, UUM.

Colin B, Gerard B, David M, Robert B (2005). Enterprises development: the challenges of starting, growing and selling businesses. London: Thomson Learning Publisher.

Cooper, A. C. (1993). Challenges in predicting new firm performance. J. Bus. Venturing. 8(3): 241-253.

Dahal H (2004). Factor analysis for soil test data: a methodological approach in environment friendly soil fertility management. Ministry of Agriculture and Cooperatives .

Dean DL, Bülent Mengüç CP (2000). Revisiting firm characteristics, strategy, and export performance relationship: a survey of the literature and an investigation of new Zealand small manufacturing firms. Ind. Mark. Manage., 29: 461-477.

Emma O (2000). The impact of reccession on UPE in Nigeria. Int. J. Edu. Dev., 20: 189-207.

Esteban L, Yancy V, Christian S (2010). Location decisions of knowledge-based entrepreneurs: Why some Catalan KISAs choose to be rural? J. Technovation.

Fabunmi M, Isah EA (2008). Managing schools in a period of global economic meltdown. Eur. J. Soc. Sc., 8:4.

Francisco L, Yi-Wen C (2006). Testing the entrepreneurial intention model on a two-country sample. Departament d'Economia de l'Empresa.

Henri J-F, (2006). Organizational culture and performance measurement systems. J. Account. Organ. Soc., 31: 77-103.

Ikeanyibe OM (2009). Development planning in nigeria: reflections on the national economic empowerment and development strategy (NEEDS) 2003-2007. J. Soc. Sci., 20(3): 197-210.

Ilian PS, Yasuo H (2005). Influence of location factors on establishment and ownership of foreign investments: The case of the Japanese manufacturing firms in Europe. Int. Bus. Rev., 14: 577-598.

Ishola RA (2008). Reducing unemployment through the informal sector:a case study of Nigeria. Eur. J. Econ. Financ Admin. Sc., 11.

Iwere N (2010, April 12). The Sun newspaper. Retrieved April 12, 2010, from The Sun Newspaper Website.

Kader R A, Mohamad M R, Ibrahim A A (2009). Success factors for small rural entrepreneurs under the one-district-one-industry programme in Malaysia. J. Contemporary Management Research. 5(2): 147-162.

Kala S S, Guanghua W (2010). Firm location choice in cities: Evidence from China, India, and Brazil. Chin. Econ. Rev., 21:113-122.

Kisfalvi $V$ (2002). The entrepreneur's character, life issues, and strategy making A field study. J. Bus. Venturing. 17: 489-518.

Kuratko DF (2005). The emergence of entrepreneurship education: development, trends, and challenges. Theory and Practice .

Kuratko DK, Hodgetts RM (2004). Entrepreneurship: theory, process \& practice. 6th Edition. United States of American: Thomson SouthWestern.

Lawal AA (2005). Management practices and organisational effectiveness in Nigeria small and medium enterprises (SMEs). Akoka, Lagos: University of Lagos.

Lahiri S, Kedia BL (2009). The effects of internal resources and partnership quality on firm performance: An examination of Indian 
BPO providers. J. Int. Manage., 15: 209-224.

MacClelland D C (1961). The achieving society. New York: Free Press.

Man TW, Lau T, Chan K (2002). The competitiveness of small and medium enterprises A conceptualization with focus on. J. Bus. Venturing, 17: 123-142.

Manufactures' Association of Nigeria. (2009, July Friday). http://www.manufacturersnigeria.org/about.htm, 820 Firms Shutdown in Nigeria. Retrieved August Saturday, 2009, from http://www.nigerianbestforum.com/index.php?topic $=38400.0$.

Martins F, Emmanuel A I (2009). Managing schools in a period of global economic meltdown. Eur. J. Sci., 8: 4.

Michael CA, Jackson DN, Wroblewski VR (2000). The impact of faking on employment tests: does forced choice offer a solution? Hum. Perform., 13(4): 371-388.

Mohd KH (2005). Small and Medium-Sized enterprises in Malaysia-Role in Isuues. Sintok: UUM Press.

Muhammad M A (2009). The Combine Effect of Market Orietation and Owner/Manager's Innovation and Business Performance of Small and medium Sized Manufacturing Firms in Pakistan. Sintok, Kedah, Malaysia: PhD Thesis, UUM.

Murphy GB, Trailer JW, Hill RC (1996). Measuring research performance in entrepreneurship. J. Bus. Res., 36: 15-23.

Nuradli RS, Hanifah AH, Shahida S, Hairunnizam W (2008). Factors influencing the islamic credit cards holders satisfaction. The Business Review, Cambridge, 11: 2.

Nwaobi GC (2009). Inflation, unemployment and nigerian families: an empirical investigation. Quant. Econ. Res. Bureau .

Ogundele OJ (2007). Introduction to entrepreneurship development, corporate government and small business management. 1st Edition. Lagos: Molofin Nominees.

Okpara JO, Wynn P (2007). Determinants of small business growth constraints in a sub-saharan african economy. SAM Adv. Manage. J.,

Olanrewaju O (2009). Entrepreneurship and performance of small-scale enterprises in Nigeria. Niger. Econ. Soc. J., 47: 2.

Orloff A (2002). Social venture partners calgary: emergence and early stages. Canadian Centre for Social Entrepreneurship.
Pelham AM (1999). Influence of environment, strategy, and market orientation on performance in small manufacturing firms. J. Bus. Res., 45: 33-46.

Rebecca EO, Benjamin JI (2009). Entrepreneurial competencies: the missing links to successful entrepreneurship in nigeria. Int. Bus. Res., 2(2): $62-71$.

Robert JT, Sammi KL (2007). Measuring chinese entrepreneurial motivation personality and environmental influences. Int. J. Entrepr. Behav. Res., 13(4): 200-221.

Sekaran U, Robert YC, Brain L D (2001). Applied business research. 1st edition. Australia: John Wiley and Sons Australian Ltd.

Shradha S, Mukherjee S, Sharan R (2005). Structural interventions for favourable sociocultural influences on india entrepreneurs. Indian.

Trent DB, Justen POC, Anastasios NB (2008). Instrumentation and motivations for organised cycling: the development of the cyclist motivation instrument (CMI). J. Sports Sci. Med., 8: 211-218.

Van De Van A (1993). The development of infrastructure for entrepreneurship: key dimensions and research implications. J. Bus. Venturing, 8: 211-230.

Wiklunda J, Shepherd D (2005). entrepreneurial orientation and small business performance: a configurational approach. J. Bus. Venturing, 20: $71-91$

William M (2009). Managerial skills for small to medium enterprises and the informal sector to enhance development and business growth. Zimbabwe.

Yanfeng Z, Si C (2008). The impacts of external factors on the growth of chinese entrepreneurial enterprises an empirical study. J. Small Bus. Enterp. Dev., 15(4): 689-703.

Yong-Hui L, Jing-Wen H, Ming-Tien T (2009). Entrepreneurial orientation and firm performance: the role of knowledge creation process. Ind. Mark. Manage., 38: 440-449. 